\title{
Pol I-transcribed hepatitis $C$ virus genome RNA replicates, produces an infectious virus and leads to severe hepatic steatosis in transgenic mice
}

\author{
Mohammod Johirul Islam ${ }^{1}$, Keisuke Hikosaka ${ }^{1,3}$, Hidenao Noritake ${ }^{1,4}$, Mohammad Khaja Mafij Uddin, \\ Mohammed Badrul Amin ${ }^{1}$, Kazushi Aото ${ }^{1}$, Yi-Xin $\mathrm{Wu}^{1}$, Eiji Sato ${ }^{1}$, Yoshimasa KobaYashi ${ }^{4}$, Takaji Wakita ${ }^{2}$, \\ and Naoyuki MiURA ${ }^{1}$ \\ ${ }^{1}$ Department of Biochemistry, Hamamatsu University School of Medicine, 1-20-1, Handa-yama, Higashi-ku, Hamamatsu 431-3192, \\ Japan; ${ }^{2}$ Department of Virology II, National Institute of Infectious Diseases, 1-23-1 Toyama, Shinjuku-ku, Tokyo 162-8640, Japan; \\ ${ }^{3}$ Kitasato Research Center for Environmental Science, 1-15-1 Kitasato, Minami-ku, Sagamihara, Kanagawa 252-0329, Japan; and ${ }^{4}$ Di- \\ vision of Hepatology, Department of Internal Medicine, 1-20-1 Handa-yama, Higashi-ku, Hamamatsu 431-3192, Japan
}

(Received 15 January 2015; and accepted 28 January 2015)

\begin{abstract}
Patients chronically infected with hepatitis $\mathrm{C}$ virus $(\mathrm{HCV})$ are at risk of developing end-stage liver disease and hepatocellular carcinoma. Development of drugs to inhibit hepatocyte damage and a vaccine against $\mathrm{HCV}$ is hampered by the lack of a small animal model. We generated mice in which the viral genome RNA was always present in the hepatocytes using a special transgene. Here we show that the HCV genome RNA transcribed by Pol I polymerase can replicate and produce infectious viruses in mice. We obtained a transgenic mouse with 200 copies per haploid which we named the A line mouse. It produced $\sim 3 \times 10^{6} \mathrm{HCV}$ RNA copies $/ \mathrm{mL}$ serum, which is at the comparable level as patients with chronic HCV infection. This mouse was immunotolerant to $\mathrm{HCV}$ and showed hepatic steatosis without any necroinflammation at the age of 6 months or hepatocellular carcinoma at the age of 15 months. Thus, the A line mouse can be used as an animal model for chronic HCV infection. This will enable better study of the abnormalities in metabolism and signal transduction in infected hepatocytes, and development of drugs that cure abnormalities.
\end{abstract}

Hepatitis C virus (HCV) is a leading cause of cirrhosis and liver cancer in the world. Recent advances in directly acting antivirals have improved virological outcomes. However, clarification of the pathogenesis of chronic HCV infection, development of the drug to cure pathological abnormalities and a vaccine to prevent $\mathrm{HCV}$ infection, are hampered by the lack of a small animal model for HCV infection. The reason why HCV infects humans but not mice was thought to be that human hepatocytes have spe-

Address correspondence to: Dr. Naoyuki Miura, Department of Biochemistry, Hamamatsu University School of Medicine, 1-20-1, Handa-yama, Higashi-ku, Hamamatsu 431-3192, Japan

Tel: +81-53-435-2326, Fax: +81-53-435-2327

E-mail:nmiura@hama-med.ac.jp cific receptors and factors for $\mathrm{HCV}$ that are absent in mice. Such molecules have been identified as CD81, SCARB1, CLDN1 and OCLN (6, 22-24). Then, it turned out that mouse has each homologue, Cd81, Scarb1, Cldn1 and Ocln, and that CD81 and OCLN must be human origin while Cldn1 and Scarb1, mouse homologues of CLDN1 and SCARB1, can work for HCV entry (5). Previously, one research group had generated a C57BL/6 transgenic mouse expressing the four human factors under an innate immune system-defective background, injected $\mathrm{HCV}$ into the tail vein and observed that only $0.4 \%$ of whole hepatocytes were infected (4). However, the virus disappeared 3 months after infection, which did not indicate a chronic infection. Recently, the ICR transgenic mouse in which human CD81 and OCLN are expressed under the alpha fetopro- 
tein enhancer/albumin promoter was created. This mouse produces infectious viruses and shows pathological manifestations of chronic hepatitis (2).

We are interested in making transgenic mice where HCV polyprotein processing, genome replication and virus particle formation occur in order to develop more effective drugs against HCV using such an animal model of chronic HCV infection. We are also interested in the production of $\mathrm{HCV}$ in large amounts for vaccine development. Previously, three groups used full-length HCV genome cDNA under the control of human amyloid $\mathrm{P}$ component promoter (16), albumin enhancer/promoter (14) and $\alpha$-antitrypsin promoter (1) to generate transgenic mice, in order to investigate the cytopathogenic roles of the viral structural and non-structural proteins seen in patients with chronic $\mathrm{HCV}$ infection. In this study, we created the HCV genome transgenic mouse by using a special transgene and succeeded in producing an infectious virus in mice. In addition, this transgenic mouse developed severe steatosis at the age of 6 months.

\section{MATERIALS AND METHODS}

Generation of the HCV genome transgenic mouse. The HCV JFH-1 genome cDNA was connected to the human Pol I promoter at the 5' end and the mouse Pol I terminator at the 3' end, and named pHH-JFH1 (15) (a gift from Dr T. Suzuki, Hamamatsu University School of Medicine). We added the Swa I sites at both ends of the pHH-JFH1 DNA (Fig. 1A). The Swa I fragment was purified after cutting with Swa I and injected into a male pronucleus of fertilised eggs as described previously $(9,10,31)$. The copy number of the transgenes in each mouse was determined using the dot blot method with the E1-NS2 fragment (nucleotides 986-2956) as a probe. Briefly, $6 \mu \mathrm{L}(5 \mu \mathrm{g})$ of mouse genome DNA was mixed with $3 \mu \mathrm{L}$ of $1.0 \mathrm{~N} \mathrm{NaOH}$, boiled for $2 \mathrm{~min}$ and then $2 \mu \mathrm{L}$ of sodium acetate and $5 \mu \mathrm{L}$ of $5 \mathrm{M} \mathrm{NaCl}$ were added. Then $4 \mu \mathrm{L}$ of DNA sample was blotted onto Nylon membrane. At the same time, 1, 2, 5, 10, 25, 50, 100, 150, 200, 250 copies/ haploid standard plasmid DNA samples were treated similarly. After ${ }^{32} \mathrm{P}$-labelled probe was hybridized overnight at $65^{\circ} \mathrm{C}$ and washed with $2 \times \mathrm{SSC}, 1 \%$ SDS at $60^{\circ} \mathrm{C}$ for $30 \mathrm{~min}$ twice, each dot was measured quantitatively by Bioimaging analyzer BAS (Fuji film, Japan). The founder mice were crossed with C57BL/6 mice, and the genotypes of transgenic mice were determined by Southern blot analysis and polymerase chain reaction (PCR) with primers
5'-AACTCGTCAGGGTGTCCAGG-3' and 5'-GGA GTTCATCCACGTGCAGC-3'. We kept the transgenic $\mathrm{A}, \mathrm{B}, \mathrm{C}, \mathrm{D}$ and $\mathrm{J}$ line mice in the homozygous conditions.

Animal studies. Research involving animals complied with protocols approved by the Hamamatsu University School of Medicine Committee of Laboratory Animal Experimentation.

Cell culture and immunostaining of HCV core protein. Human hepatoma Huh7.5.1 cells were cultured in Dulbecco's modified Eagles medium (DMEM) containing $10 \%$ foetal calf serum (FCS). The HCVcontaining fractions of sucrose density gradient or the sera from transgenic mice were inoculated to culture cells, incubated for $3 \mathrm{~h}$ and cultured for a further 2 days with complete media at $37^{\circ} \mathrm{C}$ in a $\mathrm{CO}_{2}$ incubator. The cells were fixed with $3.5 \%$ formalin in phosphate-buffered saline (PBS), and permeabilised with $0.2 \%$ Triton X-100 in PBS. Cells were incubated with rabbit HCV-Core antibody (Abbiotec, San Diego, CA, USA), followed by an incubation with Alexa 647-conjugated goat anti-rabbit IgG secondary antibody (Invitrogen, Carlsbad, CA, USA). The cells were then rinsed with PBS and counterstained with DAPI (Dojindo Molecular Technologies, Inc., Japan). The washed cells were observed with a confocal microscope FV-1000 (Olympus, Tokyo, Japan).

Immunohistochemistry and determination of the $H C V$ genome RNA copy. Liver tissues were excised from 6 and 12-month-old wild type and transgenic mice, and fixed in $10 \%$ formalin in PBS overnight for haematoxylin and eosin staining (Sigma-Aldrich) and frozen in OCT compound (Tissue Tech, Torrance, CA, USA) for Oil Red O staining (SigmaAldrich). All histological staining was performed in accordance with conventional procedures. The liver and other tissues (spleen, kidney and heart) were also frozen in OCT compound for HCV-Core antibody staining. The frozen sections $(4 \mu \mathrm{m}$ thickness) were prepared and incubated with rabbit HCV-Core antibody at room temperature for $1 \mathrm{~h}$, followed by a further incubation with Alexa 647-conjugated antirabbit IgG secondary antibody. The sections were then rinsed with PBS and counter-stained with DAPI, and observed with a confocal microscope FV-1000.

Total RNA was isolated from each tissue as described previously (8). Briefly, the liver (about $1 \mathrm{~g}$ ) or other tissues were excised from a mouse, put in 
liquid nitrogen, and cut into pieces. The tissue pieces were homogenized in guanidinium thiocyanate/ Tris/EDTA/ $\beta$-mercaptoethanol solution with Polytoron (PT 3100; KIMEMATIKA, Switzerland) and the supernatant layered onto a $5.7 \mathrm{M} \mathrm{CsCl}$ solution. Following centrifugation, using a SW41 rotor (Beckman) for $12 \mathrm{~h}$ at $27,000 \mathrm{rpm}$, the RNA pellet was washed once with $70 \%$ ethanol and dissolved in $\mathrm{H}_{2} \mathrm{O}$. The HCV RNA from each serum was purified using a QIAamp Viral RNA Mini kit (Qiagen, Hilden, Germany) according to the supplier's protocol. The RNA copy numbers of the HCV genome from the tissues and sera were determined as described previously (27). Briefly, RNA samples were subjected to real-time detection (RTD)-PCR (TaqMan, Roche, USA) and the copy numbers of the HCV RNA were determined using the Step One Plus RT-PCR system (Applied Biosystems, Bedford, MA, USA). In this system, one set of PCR primers (sense: 5'-CGGGAGAGCCATAGTGG-3' and anti-sense: 5'-AGTACCACAAGGCCTTTC G-3') and a probe (5'-CTGCGGAACCGGTGA GTACAC-[TAMRA]-3') targeting the 5' non-coding region (UTR) of HCV were used. A standard curve was constructed using a ten-fold dilution series $\left(10^{1}-10^{7}\right.$ copies $)$ of in vitro-transcribed and previously titrated synthetic HCV RNA. In this system, the detection limit was ten copies per reaction.

For determination of the HCV genome RNA replication, $40 \mu \mathrm{g}$ of the HCV NS5A inhibitor, BMS790052 (Selleck Chemicals, Houston, TX, USA) per mouse was delivered by intraperitoneal injection. Blood was collected at 0 and $24 \mathrm{~h}$ after drug administration from mock, vehicle (2\% DMSO/PBS) and drug-treated mice, and the HCV RNA copy numbers were determined from the collected sera by RTDPCR, as mentioned above.

ALT and AST measurements of the sera. The ALT and AST activities in the sera were measured using an alanine aminotransferase (ALT) and aspartate aminotransferase (AST) activity assay kits (BioVision, Milpitas, CA, USA).

Sucrose density gradient analysis of the virus. The sera after RNaseA treatment (Fig. 3A), or seven-fold concentrated sera (Fig. 3C) $(500 \mu \mathrm{L})$ from transgenic A line mice, were layered onto a continuous $20-60 \%$ (wt/vol) sucrose gradient in PBS and centrifuged at $35,000 \mathrm{rpm}$ at $4^{\circ} \mathrm{C}$ for $16 \mathrm{~h}$ using a SW41 rotor (Beckman-Coulter). Fractions $(1.1 \mathrm{~mL}$ each) were collected from the top of the tube (ten fractions in total) and the density for each fraction was deter- mined. The copy number of the HCV RNA and the infectious titre were determined from each fraction as described above and below, respectively.

Infectious titre of $\mathrm{HCV}$ in sera. The infectivity titre of the sera was determined on Huh7.5.1 cells by end point dilution and immunofluorescent detection. Briefly, each sample was serially diluted 10 -fold in DMEM and $50 \mu \mathrm{L}$ was inoculated to the Huh7.5.1 cells $\left(10^{4}\right.$ cells $)$ in a well of an eight-well micro slide glass (Matsunami Glass, Tokyo), incubated for $3 \mathrm{~h}$ and again cultured for a further 2 days with complete media at $37^{\circ} \mathrm{C}$ in a $\mathrm{CO}_{2}$ incubator. After 2 days, cells were immunostained with a rabbit $\mathrm{HCV}$ Core antibody and an Alexa 647-conjugated antirabbit IgG antibody. Infectious foci were counted and the titre was calculated and expressed as FFU/mL.

\section{RESULTS}

Creation of a transgenic mouse containing fulllength HCV genome, which produces infectious virus in vivo

RNA polymerase I (Pol I) is a cellular enzyme that transcribes pre-rRNA without the addition of either a 5' cap structure or a 3' poly (A) tail and has previously been used to make influenza virus (20) and HCV (15). Thus, in this study we used a human prerRNA (Pol I) promoter to direct expression of the whole HCV genome cDNA (JFH1 strain) in mice. The human Pol I promoter-HCV genome cDNAmouse Pol I terminator construct (15) flanked with Swa I sites (Fig. 1A), was injected into fertilised mice eggs to generate transgenic mice containing full-length HCV genome. Sixty four mice were generated and among them, seventeen were positive for HCV transgene confirmed by polymerase chain reaction (PCR) analysis. We further confirmed the presence of transgene in seventeen founder mice by Southern blot analysis (Data not shown).

Initially, we determined the transgene copy numbers in 17 transgenic mice, named A line through to $\mathrm{Q}$ line. Among these 17 lines, we maintained five mice lines (Table 1) and used these mice in subsequent experiments. The A and B lines had approximately 200 and 130 copies of transgene per haploid, respectively, while the $\mathrm{J}$ line had two copies per haploid. The HCV RNA copy numbers of A and B lines were also measured in both the liver (Fig. 1B) and sera (Fig. 1C). The A line produced $\sim 3 \times 10^{4}$ copies per $\mu \mathrm{g}$ total liver RNA and $\sim 3 \times 10^{6}$ copies per $\mathrm{mL}$ sera. The HCV RNA levels in the A line mice were comparable to that recorded in patients 


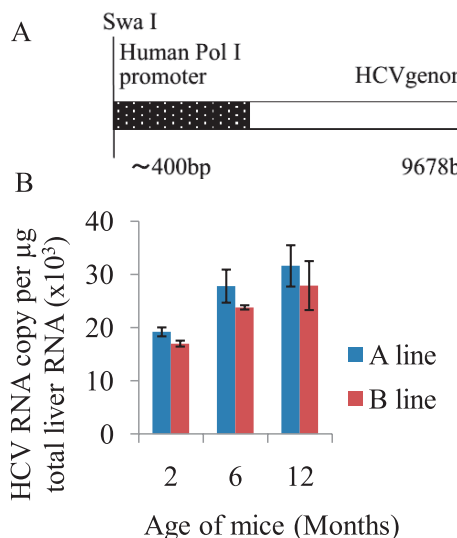

$\mathrm{D}$

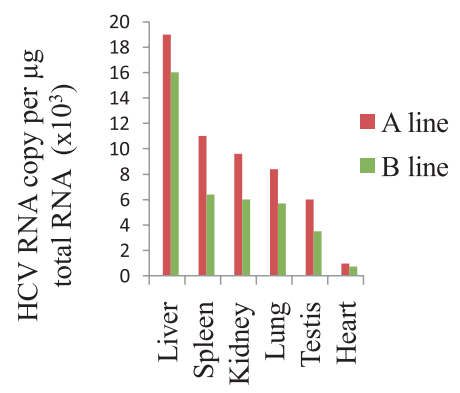

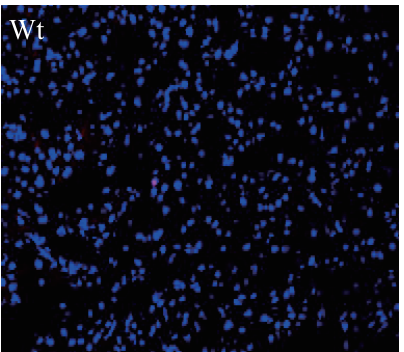

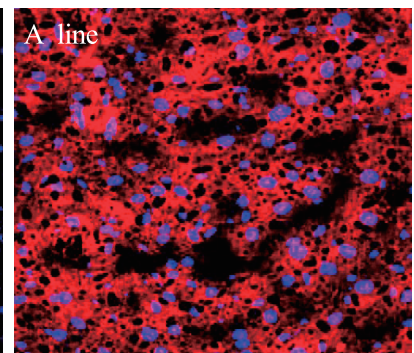

Fig. 1 The HCV genome transgenic mice produced an infectious virus. (A) Whole structure of HCV genome transgenic transgene. The Swal sites were added to both ends of the Pol I promoter and terminator. (B) HCV RNA copy number in the livers of transgenic A and B line mice. (C) HCV RNA copy number in the sera of transgenic A and B line mice. (D) HCV RNA copy number in various tissues of transgenic $A$ and $B$ line mice. (E) The immunostaining of HCV core protein in the livers obtained from wild type (Wt) and transgenic A line mice. The liver sections were stained with a rabbit HCV-Core antibody and then with an Alexa 647-conjugated anti-rabbit IgG secondary antibody. The sections were counter-stained with DAPI (blue). The HCV core protein (red) was strongly detected in the cytoplasm of all hepatocytes of transgenic A line mice, whereas the liver of Wt mouse showed negative result for HCV core protein. Photographs were obtained at $200 \mathrm{X}$ magnification. For panels $(\mathbf{B})$ and $(\mathbf{C})$, data shown are mean \pm S.D. of two individual mice of each group of each mouse line.

Table 1 Copy numbers of transgene and HCV RNA in the liver and sera of transgenic mice

\begin{tabular}{cccc}
\hline Line name & $\begin{array}{c}\text { DNA copies of transgene } \\
\text { per haploid }\end{array}$ & $\begin{array}{c}\text { HCV RNA copy in the liver } \\
\text { (copies/ } \mu \text { g of total liver RNA) }\end{array}$ & $\begin{array}{c}\text { HCV RNA copy in sera } \\
\text { (copies/mL) }\end{array}$ \\
\hline A & $\sim 200$ & $2.78 \pm 0.31 \times 10^{4}$ & $3.63 \pm 0.06 \times 10^{6}$ \\
B & $\sim 130$ & $2.38 \pm 0.05 \times 10^{4}$ & $2.60 \pm 0.45 \times 10^{6}$ \\
C & $\sim 45$ & $1.20 \pm 0.06 \times 10^{3}$ & $1.48 \pm 0.07 \times 10^{5}$ \\
D & $\sim 25$ & $7.86 \pm 0.28 \times 10^{2}$ & $1.44 \pm 0.27 \times 10^{5}$ \\
J & $\sim 2$ & $3.22 \pm 0.61 \times 10^{2}$ & $4.92 \pm 3.67 \times 10^{4}$ \\
\hline
\end{tabular}

Values in copy numbers are expressed as mean \pm S.D from two individual mice for each group.

with chronic $\mathrm{HCV}$ infection. The B line produced slightly less titre, while the $\mathrm{D}$ line and the $\mathrm{J}$ line produced about $1 / 25$ th and $1 / 75$ th of the A line, respectively (Table 1). Next, the numbers of $\mathrm{HCV}$ RNA copies were measured in various tissues of both the A and B line mice and found to be specifically expressed in the liver, spleen, kidney, lung, testis and heart (Fig. 1D). Immunohistochemical staining showed conclusively that the liver of transgenic A line mice was strongly positive for the HCV-Core antibody (Fig. 1E). Other tissues were also positive for the antibody, but the fluorescence intensities were proportional to the HCV RNA copy number (Fig. 2). The differences in RNA copy numbers is likely due to the absence or low expression of miR122, which stabilises the HCV RNA in tis- 

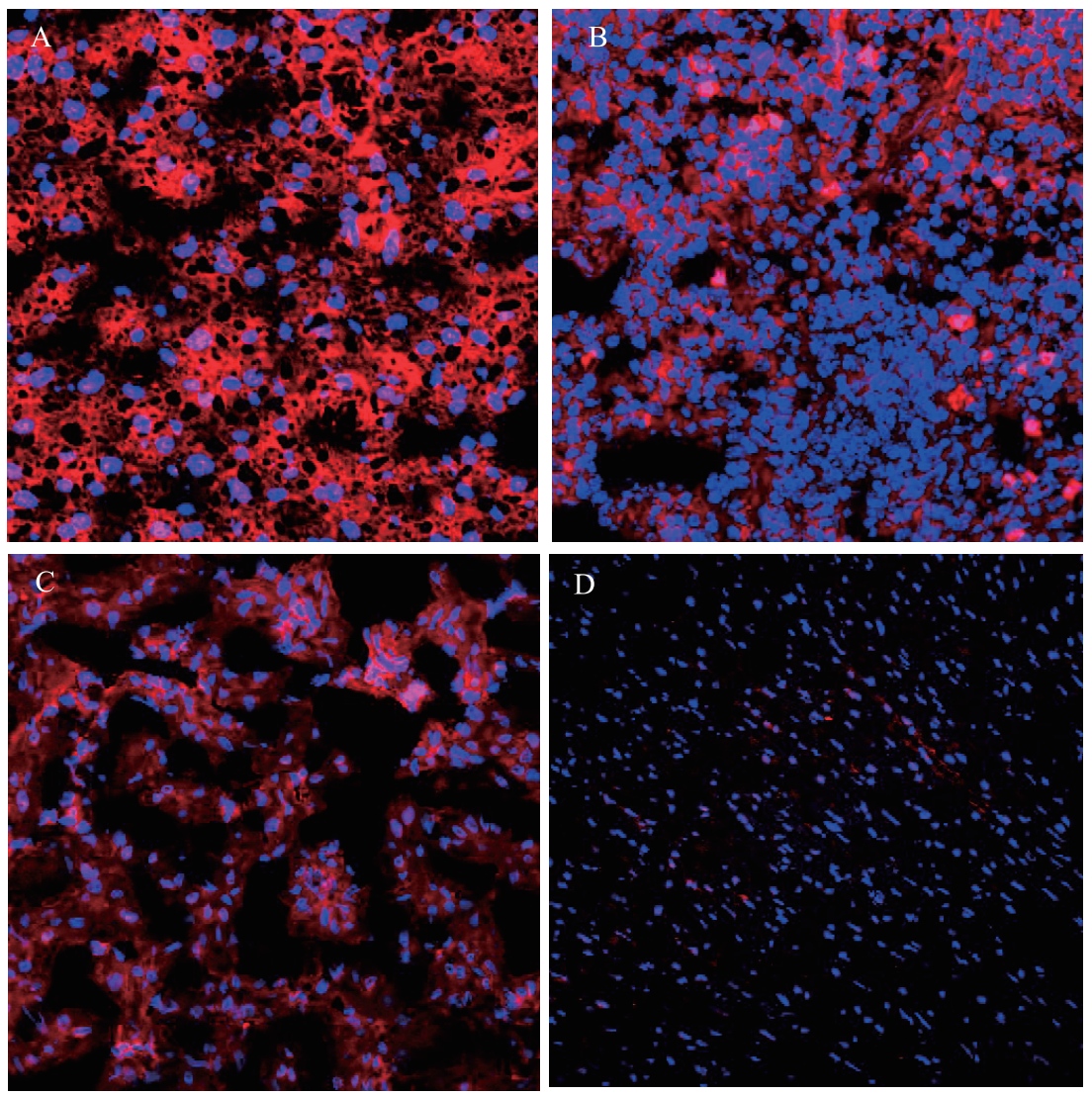

Fig. 2 The immunostaining of HCV core protein in various tissues of the transgenic A line mouse. The sections of liver (A), spleen (B), kidney (C) and heart (D) were stained with a rabbit HCV-Core antibody and then with an Alexa 647-conjugated anti-rabbit IgG antibody. The sections were counter-stained with DAPI (blue). The HCV core protein (red) was strongly detected in the liver section compared to other tissues. Photographs were obtained at 200X magnification.

sues other than the liver $(7,26)$. As the apoE protein is an essential factor for the production of $\mathrm{HCV}$ particles, only the liver is expected to produce an infectious virus via the apoE protein $(2,7,13,26)$.

\section{Replication of the transcribed HCV genome RNA}

Next, we characterised the virus particles in sera of A line mice. Sucrose density gradient analysis showed the density of the peak fraction of $\mathrm{HCV}$ RNA to be $1.17 \mathrm{~g} / \mathrm{mL}$, even after RNaseA treatment (Fig. 3A). The infectivity of the virus was checked using Huh7.5.1 hepatoma cells. Cytoplasmic staining was strongly positive for the $\mathrm{HCV}$-Core antibody (Fig. 3B). The infectious titre from each fraction of the sucrose density gradient of seven-fold concentrated sera obtained from A line mice was determined (Fig. 3C). The peak of infectivity exhibited at a density of $1.12 \mathrm{~g} / \mathrm{mL}$ that was slightly lower than that of the HCV RNA peak. The HCV RNA copies in sera were compared with the infectious titre and it was found that the specific infectivity was approx- imately $2 \times 10^{-4}$ focus-forming units (FFU)/RNA copy (Table 2).

Furthermore, we investigated whether the $\mathrm{HCV}$ genome RNA, which was transcribed by Pol I, could replicate. After injecting a $\mathrm{HCV}$ NS5A inhibitor, BMS-790052, the HCV RNA copy numbers were found to decrease to one-third in both the liver and sera of transgenic A line mice after $24 \mathrm{~h}$ (Fig. 3D and $3 \mathrm{E}$ ). We therefore concluded that the transcribed $\mathrm{HCV}$ genome RNA could replicate and produce infectious viruses.

Pathological changes in the transgenic A line mice Finally, we observed the pathological changes in the A line mice. Haematoxylin and eosin staining showed no infiltration of the inflammatory immune cells and no gross disarrangement of the hepatic acini. In contrast to wild type mice, many hepatocytes containing vacuoles were observed in 6 and 12 month old transgenic mice (Fig. 4A-D), and lipid storage in vacuoles of hepatocytes was observed. These vacuo- 
A

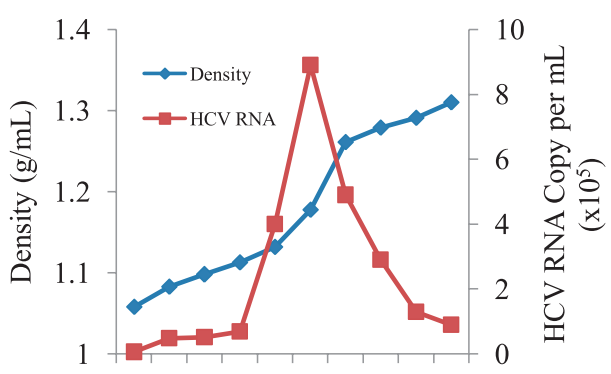

$\begin{array}{lllllllllll}1 & 2 & 3 & 4 & 5 & 6 & 7 & 8 & 9 & 10\end{array}$ Fractions

C

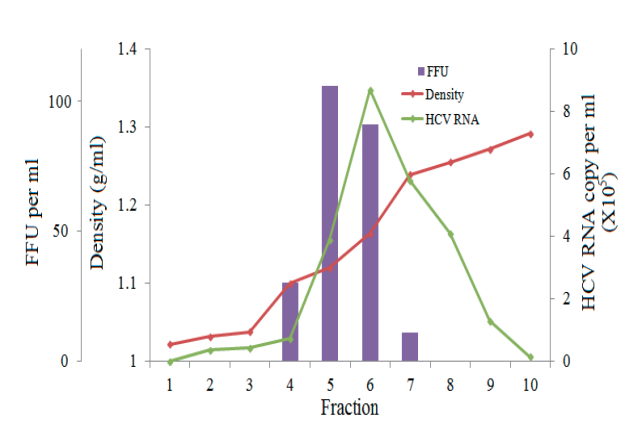

B
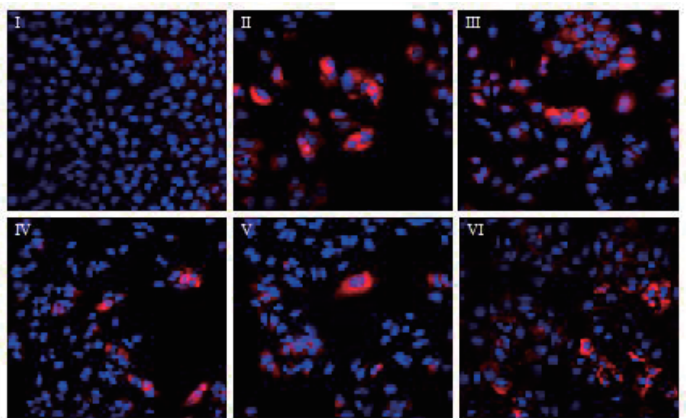

E
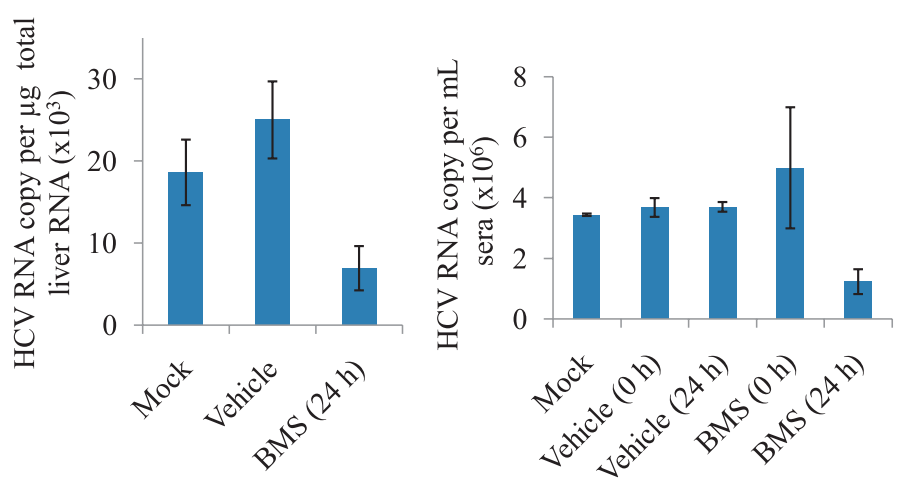

Fig. 3 Characterisation of HCV in sera of the transgenic A line mice. (A) Sucrose density gradient analysis from the transgenic sera after RNaseA treatment. The density of peak fraction of HCV genome RNA is $1.17 \mathrm{~g} / \mathrm{mL}$. (B) The infected Huh7.5.1 cells were stained with a rabbit HCV-Core antibody and then with an Alexa 647-conjugated anti-rabbit IgG antibody. The cells were then rinsed with PBS and counter-stained with DAPI (blue). The HCV core protein (red) was strongly detected in the cytoplasm of infected cells. I, uninfected; II-VI, infected cells with sera obtained from different transgenic A line mice. Photographs were obtained at 200X magnification. (C) Infectious titre from each fraction of sucrose density gradient analysis of sera obtained from transgenic A line mice. (D) HCV RNA copy numbers in the liver of transgenic A line mice after a HCV NS5A inhibitor, BMS-790052 injection. (E) HCV RNA copy numbers in the sera of transgenic A line mice after a HCV NS5A inhibitor, BMS-790052 injection. For panels (D) and (E), data shown are mean \pm S.D. of three individual mice of each group. Mock, untreated mice; Vehicle, drug vehicle treated mice; BMS, drug treated mice.

Table 2 Infectivity of sera obtained from transgenic A line mice

\begin{tabular}{cccc}
\hline $\begin{array}{c}\text { Mice No } \\
\text { (Age) }\end{array}$ & $\begin{array}{c}\text { HCVRNA } \\
\text { (copies/mL) }\end{array}$ & $\begin{array}{c}\text { Infectivity titre } \\
(\text { FFU/mL) }\end{array}$ & $\begin{array}{c}\text { Specific infectivity } \\
\text { (FFU/RNA copy) }\end{array}$ \\
\hline 6930 (4 months) & $5.0 \times 10^{6}$ & $10.0 \times 10^{2}$ & $2.0 \times 10^{-4}$ \\
6918 (4 months) & $1.8 \times 10^{6}$ & $4.0 \times 10^{2}$ & $2.3 \times 10^{-4}$ \\
7049 (6 months) & $2.4 \times 10^{6}$ & $6.0 \times 10^{2}$ & $2.5 \times 10^{-4}$ \\
7051 (6 months) & $3.3 \times 10^{6}$ & $8.0 \times 10^{2}$ & $2.4 \times 10^{-4}$ \\
\hline
\end{tabular}

FFU, focus forming unit.

lating lesions appeared in the cytoplasm of hepatocytes of transgenic A line mice and were stained positive by Oil Red O (Fig. 4E-H). It indicated that these lesions are steatosis, and steatosis became more severe with the increasing age of the transgenic mice (Fig. 4E-H). In contrast, no steatosis was observed in the livers of wild type mice. In addition, we observed that four 15-month-old mice of trans- genic A line were free of hepatocellular carcinoma (data not shown). Furthermore, we measured changes in levels of alanine aminotransferase (ALT) and aspartate aminotransferase (AST) enzymes, which are indicators of hepatocyte damage, and found no increases (Table 3). 


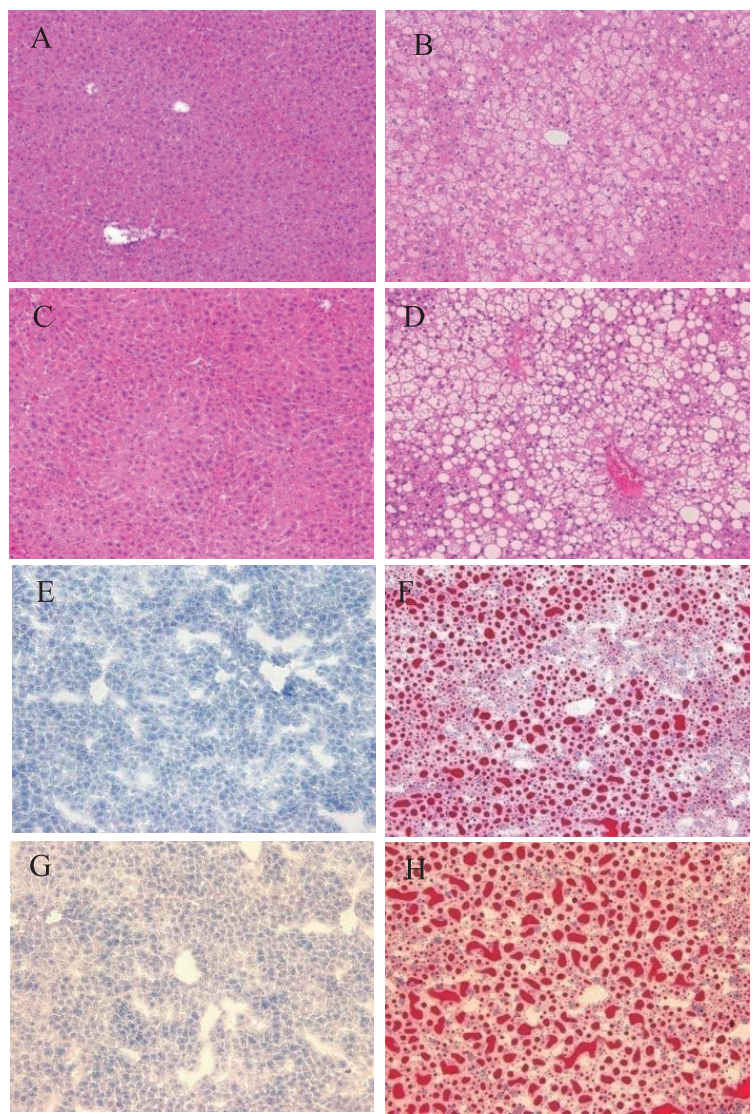

Fig. 4 The transgenic mouse showed hepatic steatosis. Liver sections from wild type (A, C) and transgenic A line (B, D) mice at the ages of $6(\mathbf{A}, \mathbf{B})$ and $12(\mathbf{C}, \mathbf{D})$ months were stained with haematoxylin and eosin. No infiltration of mononuclear cells was detected and all hepatocytes contained vacuoles in the transgenic mice, but not in wild type mice. Oil Red $O$ staining of livers from wild type $(\mathbf{E}, \mathbf{G})$ and transgenic $A$ line $(\mathbf{F}, \mathbf{H})$ mice at the ages of $6(\mathbf{E}, \mathbf{F})$ and $12(\mathbf{G}, \mathbf{H})$ months. A large amount of lipid was deposited in vacuoles of hepatocytes in the transgenic mice, but not in wild type mice. Photographs were obtained at 200X magnification.

\section{DISCUSSION}

Many researchers $(1,3,11,12,14,16-19,21,25$, 28-30) have produced transgenic mice expressing various kinds of $\mathrm{HCV}$ proteins, including the inducible (Cre/loxP or Tet) system. Interestingly, when a polyprotein open reading frame is expressed under the albumin enhancer/promoter, hepatocellular carcinoma (HCC) develops in $13 \%$ of the mice older than 13 months (14). In all such transgenic mice no viral particles were produced since their transgenes did not contain complete 5' and 3' UTRs. However, in this study we used Pol I promoter first time for producing $\mathrm{HCV}$ in vivo and succeeded to produce infectious virus in transgenic mice. In addition, our
Table 3 ALT and AST activity in sera

\begin{tabular}{ccc}
\hline Mice & ALT (unit/litre) & AST (unit/litre) \\
\hline Wild-type, 6 months & $8.08 \pm 0.79$ & $16.02 \pm 0.28$ \\
Wild-type, 12 months & $14.88 \pm 6.48$ & $15.72 \pm 3.58$ \\
Transgenic A, 6 months & $8.17 \pm 1.76$ & $18.01 \pm 4.90$ \\
Transgenic A, 12 months & $8.50 \pm 1.39$ & $15.76 \pm 2.24$ \\
\hline
\end{tabular}

Values are expressed as mean \pm S.D. from three individual mice for each group.

transgenic mice developed severe hepatic steatosis at the age of 6 months, which is one of the characteristic features of chronic $\mathrm{HCV}$ infection. As shown in Fig. 1E, the core protein is present in large amounts in all hepatocytes. We expect that other structural and non-structural proteins of $\mathrm{HCV}$ were also present in these hepatocytes. As shown in Fig. 3D and 3E, one-third of the genome RNA was synthesised by Pol I polymerase, while the other two-thirds were synthesised by replication (viral RNA-dependent RNA polymerase). From this result, we concluded that HCV RNA is being replicated in our transgenic mice.

Our transgenic mice were immunotolerant to HCV. The hepatocytes that mimic the post-entry state of HCV infection were not destroyed by immune reaction and the ALT and AST levels in sera did not increase (Table 3 ). In this study, the mice with a high copy number of transgene produce sufficiently high titres of infectious viruses, compared to the patients with chronic $\mathrm{HCV}$ infection. In the liver of our A line mouse, transcribed HCV RNA could undergo polyprotein processing, genome RNA replication and virus assembly, in a manner similar to that reported for $\mathrm{HCV}$ in infection of human hepatocytes. Unlike immortalised hepatocytes or primary hepatocytes that generally tend to lower expression of miR122 (7), ApoE (26) and P450 Cyp proteins over time, the protein levels of the A line mouse are extremely high and provide this mouse line a fully differentiated state in which we can study potential drug treatments for HCV. Moreover, these high levels of proteins should support better analysis and detection methods to further study the molecular mechanisms of polyprotein processing, genome RNA replication and viral assembly. Furthermore, since the A line mouse clearly showed steatosis, which is evidence of metabolic abnormality in HCV infections, this model could also be used to investigate dysregulation of metabolism and signal transduction in infected hepatocytes.

Significantly, when whole-genome cDNAs for wild type $1 \mathrm{a}, 1 \mathrm{~b}$ and $2 \mathrm{~b}$ substrains were replaced in 
the JFH1 (2a substrain) cDNA position of the transgene, a large amount of the infectious virus of each $\mathrm{HCV}$ substrain would be produced in the mice, which cannot be achieved using hepatoma cell culture lines. Consequently, our transgenic mouse could provide a good model system to study potential drug treatments against the different HCV infections in humans.

Last but not least, the application of this system to other animals, including cattle and horses, could produce an extremely large amount of virus, which would be useful for vaccine development.

\section{Acknowledgements}

We thank Drs. Tetsuro Suzuki and Haruhiko Sugimura for a gift of the pHH-JFH1 plasmid DNA and advice for virological and pathological analyses, respectively. This work was supported by grants of Researchin-Aid from the Ministry of Education, Sciences, Sports, Culture and Technology of Japan and from the Ministry of Health and Welfare of Japan.

\section{REFERENCES}

1. Alonzi T, Agrati C, Costabile B, Cicchini C, Amicone L, Cavallari C, Rocca CD, Folgori A, Fipaldini C, Poccia F, Monica NL and Tripodi M (2004) Steatosis and intrahepatic lymphocyte recruitment in hepatitis $\mathrm{C}$ virus transgenic mice. $J$ Gen Virol 85, 1509-1520.

2. Chen J, Zhao Y, Zhang C, Chen H, Feng J, Chi X, Pan Y, Du J, Guo M, Cao H, Chen H, Wang Z, Pei R, Wang Q, Pan L, Niu J, Chen X and Tang H (2014) Persistent hepatitis C virus infection and hepatopathological manifestations in immune-competent humanized mice. Cell Research 24, 10501066.

3. Chiyo T, Sekiguchi S, Hayashi M, Tobita Y, Kanegae Y, Saito I and Kohara M (2011) Conditional gene expression in hepatitis $\mathrm{C}$ virus transgenic mice without induction of severe liver injury using a non-inflammatory Cre-expressing adenovirus. Virus Res 160, 89-97.

4. Dorner M, Horwitz JA, Donovan BM, Labitt RN, Budell WC, Frilling T, Vogt A, Catanese MT, Satoh Takashi, Kawai T, Akira S, Law M, Rice CM and Ploss A (2013) Completion of the entire hepatitis $\mathrm{C}$ virus life cycle in genetically humanized mice. Nature 501, 237-241.

5. Dorner M, Horwitz JA, Robbins JB, Barry WT, Feng Q, Mu K, Jones CT, Schoggins JW, Catanese MT, Burton DR, Law M, Rice CM and Ploss A (2011) A genetically humanized mouse model for hepatitis C virus infection. Nature 474, 208-211.

6. Evans MJ, Hahn TV, Tscherne DM, Syder AJ, Panis M, Wolk B, Hatziioannou T, Mckeating JA, Bieniasz PD and Rice CM (2007) Claudin-1 is a hepatitis C virus co-receptor required for a late step in entry. Nature 446, 801-805.

7. Frentzen A, Anggakusuma, Gurlevik E, Hueging K, Knocke S, Ginkel C, Brown RJP, Heim M, Dill MT, Kroger A, Kalinke U, Kaderali L, Kuehnel F and Pietschmann T (2014) Cell entry, efficient RNA replication, and production of infectious HCV progeny in mouse liver-derived cells. Hepatology 59,
$78-88$.

8. Green MR and Sambrook J (2012) Purification of total RNA from mammalian cells and tissues. In: Molecular Cloning. A Laboratory Manual. 4th edition, pp.351-353, Cold Spring Harbor Labortory Press.

9. Hikosaka K, Noritake H, Kimura W, Sultana N, Sharkar MT, Tagawa Y, Uezato T, Kobayashi Y, Wakita T and Miura N (2011) Expression of human factors CD81, claudin-1, scavenger receptor, and occludin in mouse hepatocytes does not confer susceptibility to HCV entry. Biomed Res (Tokyo) 32, $143-150$.

10. Ichihara T, Komagata Y, Yang XL, Uezato T, Enomoto K, Koyama K, Miyazaki J, Sugiyama T and Miura N (2001) Resistance to fulminant hepatitis and carcinogenesis conferred by overexpression of Retinoblastoma protein in mouse liver. Hepatology 33, 948-955.

11. Kato T, Miyamoto M, Date T, Yasui K, Taya C, Yonekawa H, Ohue C, Yagi S, Seki E, Hirano T, Fujimoto J, Shirai T and Wakita T (2003) Repeated hepatocyte injury promotes hepatic tumorgenesis in hepatitis $\mathrm{C}$ virus transgenic mice. Cancer Sci 94, 679-685.

12. Kawamura T, Furusaka A, Koziel MJ, Chung RT, Wang TC, Schmidt EV and Liang TJ (1997) Transgenic expression of hepatitis C virus structural proteins. Hepatology 25, 10141021.

13. Lee JY, Acosta EG, Stoeck IK, Long G, Hiet MS, Mueller B, Fackler OT, Kallis S and Bartenschlager R (2014) Apolipoprotein $\mathrm{E}$ likely contributes to a maturation step of infectious hepatitis $\mathrm{C}$ virus particles and interacts with viral envelope glycoproteins. J Virol 88, 12422-12437.

14. Lerat H, Honda M, Beard MR, Loesch K, Sun J, Yang Y, Okuda M, Gosert R, Xiao SY, Weinman SA and Lemon SM (2002) Steatosis and liver cancer in transgenic mice expressing the structural and nonstructural proteins of hepatitis $\mathrm{C}$ virus. Gastroenterology 122, 352-365.

15. Masaki T, Suzuki R, Saeed M, Mori K, Matsuda M, Aizaki H, Ishii K, Maki N, Miyamura T, Matsuura Y, Wakita T and Suzuki T (2010) Production of infectious hepatitis $\mathrm{C}$ virus by using RNA polymerase I-mediated transcription $J$ Virol 84 , 5824-5835.

16. Matsuda J, Suzuki M, Nozaki C, Shinya N, Tashiro K, Mizuno K, Uchinuno Y and Yamamura K (1998) Transgenic mouse expressing a full-length hepatitis C virus cDNA. Jpn J Cancer Res 89, 150-158.

17. Moriya K, Fujie H, Shintani Y, Yotsuyanagi H, Tsutsumi T, Ishibashi K, Matsuura Y, Kimura S, Miyamura T and Koike K (1998) The Core protein of hepatitis C virus induces hepatocellular carcinoma in transgenic mice. Nat Med 4, 10651067.

18. Moriya K, Yotsuyanagi H, Shintani Y, Fujie H, Ishibashi K, Matsuura Y, Miyamura T and Koike K (1997) Hepatitis C virus Core protein induces hepatic steatosis in transgenic mice. $J$ Gen Virol 78, 1527-1531.

19. Naas T, Ghorbani M, Maya IA, Lapner M, Kothary R, Repentigny YD, Gomes S, Babiuk L, Giulvi A, Soare C, Azizi A and Mitoma FD (2005) Characterization of liver histopathology in a transgenic mouse model expressing genotype 1a hepatitis $\mathrm{C}$ virus Core and envelope proteins 1 and 2. $J$ Gen Virol 86, 2185-2196.

20. Neumann G, Watanabe T, Ito H, Watanabe S, Goto H, Gao P, Hughes M, Perez DR, Donis R, Hoffmann E, Hobom G and Kawaoka Y (1999) Generation of influenza A viruses entirely from cloned cDNAs. Proc Natl Acad Sci USA 96, 93459350 . 
21. Pasquinelli C, Shoenberger JM, Chung J, Chang KM, Guidotti LG, Selby M, Berger K, Lesniewski R, Houghton M and Chisari FV (1997) Hepatitis C virus core and E2 protein expression in transgenic mice. Hepatology 25, 719-727.

22. Pileri P, Uematsu Y, Campagnoli S, Galli G, Falugi F, Petracca R, Weiner AJ, Houghton M, Rosa D, Grandi G, Abrignani S (1998) Binding of hepatitis C virus to CD81. Science 282, 938-941.

23. Ploss A, Evans MJ, Gaysinskaya VA, Panis M, You H, Jong YPD and Rice CM (2009) Human occludin is a hepatitis C virus entry factor required for infection of mouse cells. $\mathrm{Na}$ ture 457, 882-886.

24. Scarselli E, Ansuini H, Cerino R, Roccasecca RM, Acali S, Filocamo G, Traboni C, Nicosia A, Cortese R, Vitelli A (2002) The human scavenger receptor class B type I is a novel candidate receptor for the hepatitis $\mathrm{C}$ virus. EMBO J 21, 5017-2025.

25. Takaku S, Nakagawa Y, Shimizu M, Norose Y, Maruyama I, Wakita T, Takano T, Kohara M and Takahashi H (2003) Induction of hepatic injury by hepatitis $\mathrm{C}$ virus-specific $\mathrm{CD} 8^{+}$ murine cytotoxic $\mathrm{T}$ lymphocytes in transgenic mice expressing the viral structural genes. Biochem Biophys Res Commun 301, 330-337.

26. Vogt A, Scull MA, Friling T, Horwitz JA, Donovan BM, Dorner M, Gerold G, Labitt RN, Rice CM and Ploss A (2013) Recapitulation of the hepatitis $\mathrm{C}$ virus life-cycle in engineered murine cell lines. Virology 444, 1-11.

27. Wakita T (2009) Isolation of JFH-1 strain and development of an HCV infection system. Methods Mol Biol 510, 305327.

28. Wakita T, Katsume A, Kato J, Taya C, Yonekawa H, Kanegae Y, Saito I, Hayashi Y, Koike M, Miyamoto M, Hiasa Y and Kohara M (2000) Possible role of cytotoxic T cells in acute liver injury in hepatitis $\mathrm{C}$ virus cDNA transgenic mice mediated by Cre/loxP system. J Med Virol 62, 308-317.

29. Wakita T, Taya C, Katsume A, Kato J, Yonekawa H, Kanegae Y, Saito I, Hayashi Y, Koike M and Kohara M (1998) Efficient conditional transgenic expression in hepatitis $\mathrm{C}$ virus cDNA transgenic mice mediated by the Cre/loxP system. $J$ Biol Chem 273, 9001-9006.

30. Wang A.G, Lee DS, Moon HB, Kim JM, Cho KH, Choi SH, Ha HL, Han YH, Kim DG, Hwang SB and Yu DY (2009) Non-structural $5 \mathrm{~A}$ protein of hepatitis $\mathrm{C}$ virus induces a range of liver pathology in transgenic mice. J Pathol 219, 253262

31. Wang B, Hikosaka K, Sultana N, Sharkar MT, Noritake H, Kimura W, Wu YX, Kobayashi Y, Uezato T and Miura N (2012) Liver tumor formation by a mutant retinoblastoma protein in the transgenic mice is caused by an upregulation of c-Myc target genes. Biochem Biophys Res Commun 417, 601-606. 